\title{
Design and Fabrication of the Single Polepiece Magnetic Electron Lens of Truncated Cone Polepiece Shape
}

\author{
Muna A. Al-Khashab* \\ Abdullah I. Mostafah* and Issam I. Ismail** \\ *Professor Department of Physics, College of Science, Mosul University. \\ **Department of Mechanical Engineering, College of Engineering, University of Mosul
}

\begin{abstract}
The magnetic electron objective lens is of a great importance which limit the resolving power of the electron microscope.

The present work investigates the objective focal properties of a single polepiece magnetic electron lens of truncated cone polepiece shape of the selected geometrical dimensions for practical applications. The lens has been fabricated consist of cast shield made of mild steel combined with exciting isolated cooper coil of 500 turns.

The theoretical and experimental results presented the magnetic flux density distribution and the objective focal properties of the lens, in mode of operation when the direction of incident electrons beam facing the lens back plate of the lens.

Moreover, the theoretical and experimental results are in a good agreements.
\end{abstract}

Keywords: electron optics, magnetic lens fabrication, design of magnetic lens, objective properties, low voltage scanning electron microscope.
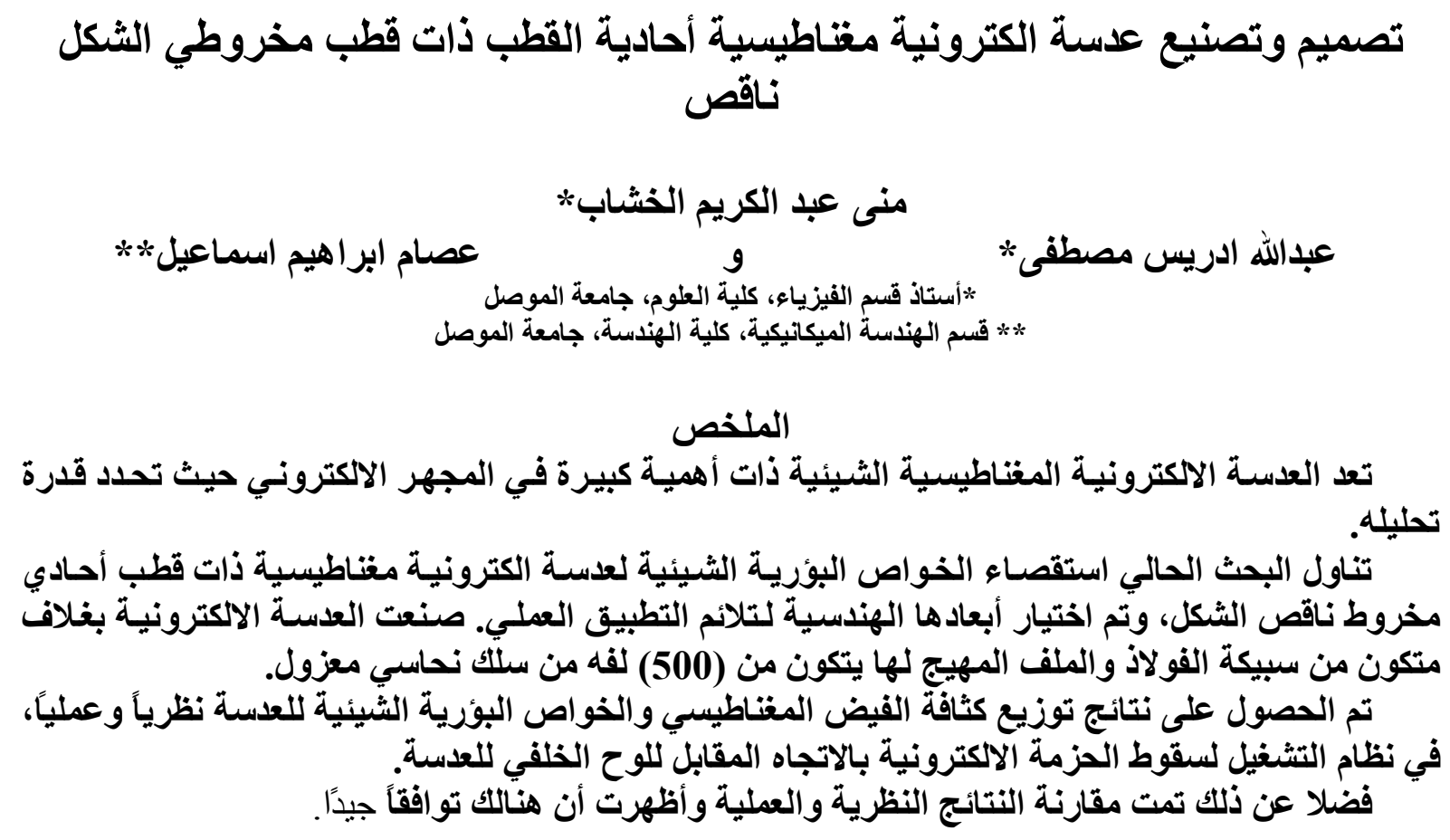

Received: $11-1$ - 2010

Accepted: $4-7$ - 2010 


\section{Introduction}

The rapid developments of integrated circuits and the increasing availability of dedicated minicomputers is the beginning to have an impact, not only on the design of the electron microscope itself, but also on the operation of the instruments [1]. As technology improves new possibilities, often unexpected, emerge for the design of the electron microscope magnetic lenses. The axial flux density distribution of a single polepiece magnetic electron lens is asymmetrical; it rises slowly to the peak at the tip of the pole face and falls rapidly within the polepiece itself [2]. The field distribution and the focal properties of the single polepiece lenses differ appreciably from those of double polepiece lenses, resulting in unusual focal properties [3].

In a single polepiece lens there are two possible directions for the electron beam to enter the field; these give rise to different focal properties [4]. For rays proceeding in either directions, the geometry of the polepiece plays an important role in determining the best focal properties.

The effect of the polepiece geometry on the degree of asymmetry of the axial magnetic flux density distribution for single polepiece of truncated cone shape lens has not been investigated experimentally in detail. An investigation of the field distribution of double polepiece magnetic electron lenses was made some time ago by Liebmann [5], later by AlObaidi [6] and more recently for a single polepiece lens was fabricated as a compound lens by Mohammed [7].

The present paper discusses the axial magnetic flux density distribution and the performance of the electron optical properties of the experimental magnetic lens with single pole of truncated cone polepiece shape.

\section{2- Fabrication and measurement}

The fabricated single polepiece lens and its geometrical parameters shown in Figure 1 was constructed, which consists of cast shield made of mild steel, it has simple geometrical shape of truncated cone polepiece of taper angle equals $53^{\circ}[8]$.

The magnetic field is generated by a rectangular cross-sectional coil cooled by water. The coil has resistance of $5.55 \Omega$ consists of 500 turns of isolated copper wire of gauge 19 SWG. The cooling water circulated inside the copper pipe directly around the coil, which is separated from the lens casting by gaps of $10 \mathrm{~mm}$, and away from the iron shroud of about $5 \mathrm{~mm}$. The temperature of the cooling water through experimental work is between $(10-25)^{\circ} \mathrm{C}$. The bore diameter in the snout of polepiece was made of $7 \mathrm{~mm}$, a large lens bore diameter is practically preferred in order to insert the specimen stage and the probe of the Teslameter inside the lens. Figure 2 shows a photograph of the fabricated lens, iron contour and

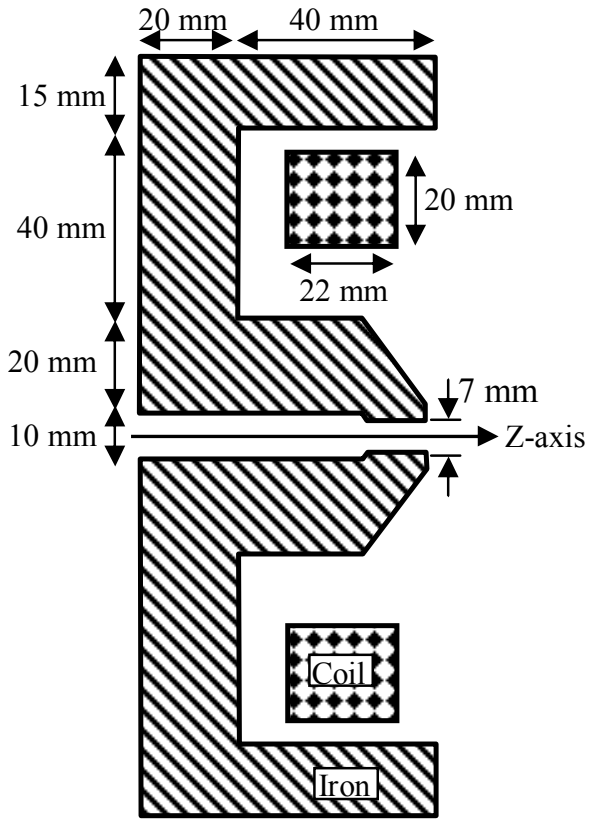

Fig. 1. Cross section of the experimental single polepiece lens of truncated polepiece shape. the energizing coil. Figure 3 shows a photograph of setting the experimental instruments. 


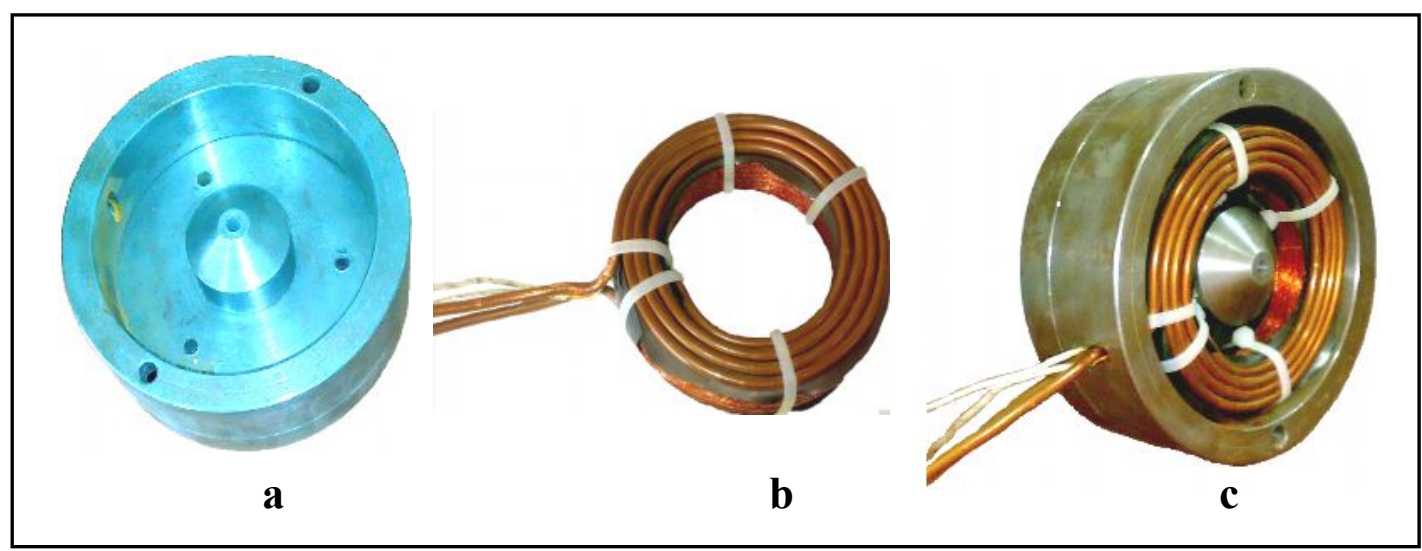

Fig. 2: Photograph of the fabricated lens and its components shows: (a) the iron contour, (b) the energizing coil and (c) the complete lens.

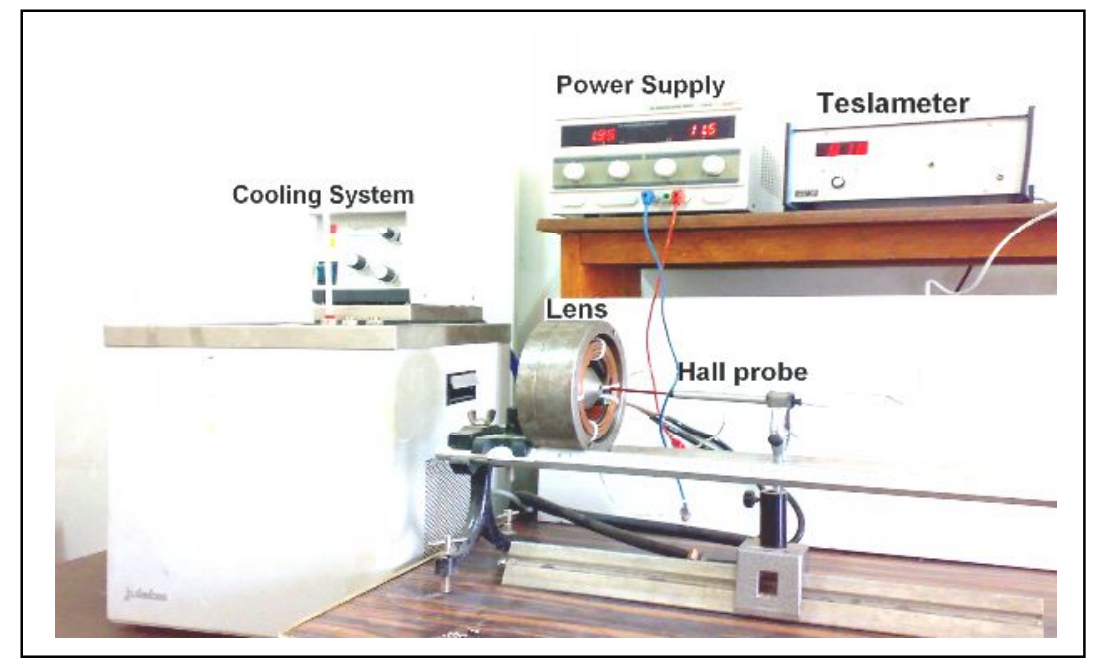

Fig. 3: Setting of the experimental instrument

\subsection{The results}

The axial magnetic flux density distribution of the lens was measured experimentally by means of Digital Teslameter (Model DGM-102) using a Hall-effect probe. The field distribution was taken at low and high excitation $\mathrm{NI}=1 \mathrm{kA}-\mathrm{t}$, and $\mathrm{NI}=2 \mathrm{kA}-\mathrm{t}$ respectively.

In order to investigate the performance of the fabricated lens theoretically, it is important to design this lens using the AMAG program based on finite element method (FEM) developed by [9], and was modified by [10] The program essentially uses the same algorithm of Munro's program [11]; it uses the "Cholesky decomposition method" combined with the "Conjugate gradient method". The analysis is based on dividing the upper half of

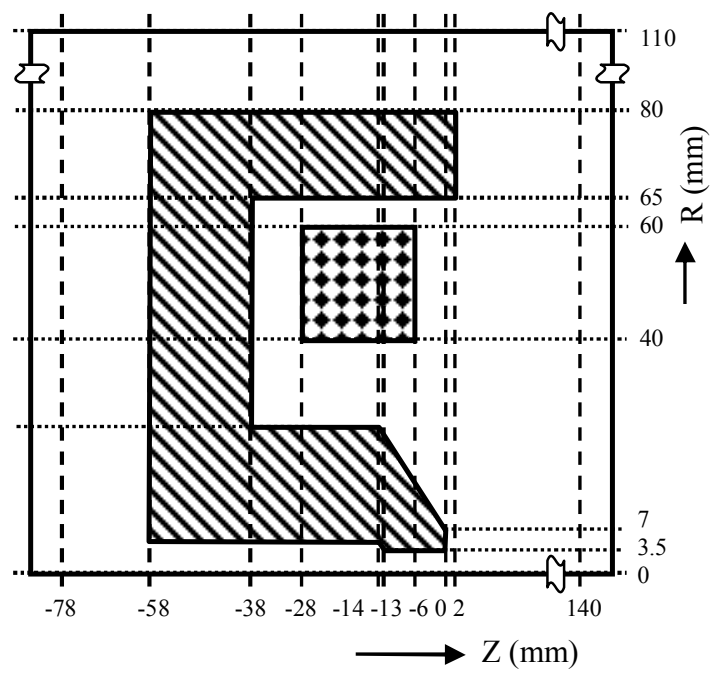

Fig. 4. The finite element mesh specification of the single polepiece magnetic electron lens. 
the cross-section for the lens (see figure 1) into quadrilateral areas so as to make the lens geometry correctly specified, shown in Figure 4. This coarse mesh is sub-divided into small quadrilateral areas to the fine meshes automatically by the same program.

Figure 5 shows the comparison between the results of the axial magnetic flux density distribution $B_{z}$ of the lens as a function of axial distance $z$, at low and high excitations. These results are obtained by using program AMAG [9], and that measured experimentally by using digital teslameter model DGM102. The results in both cases appear to be in a good agreement with each other.

In order to examine the flux leakage out the structure of the lens, the magnetic flux lines trajectories of the lens are calculated by the aid of program Flux [11]. It is modified by [12] using the magnetic flux density values at each mesh point as input data at constant excitation $\mathrm{NI}=2 \mathrm{kA}-\mathrm{t}$ as shown in Figure 6. It is seen from this figure that these lines are nearly incident normally at the surface of the pole and becomes parallel to each other inside the polepiece structure.

The fabricated lens is very satisfactory and shows that this lens may be regarded to a good approximation as objective lens, the properties of which are readily calculated analytically.

\section{Objective focal properties of the lens}

The fabricated magnetic single polepiece lens leads to a marked reduction in the objective properties; it is therefore, useful to represent its focal properties in term of accelerating voltage. The electron optical properties of the lens have been calculated by the aid of program M21 [11] using Simpson rule at different values of accelerating voltage of the electron source $V_{a}$, where $V_{a}$ is calculated from the relation $\left[V_{r}=V_{a}\left(1+10^{-6} V_{a}\right)\right]$ and $V_{r}$ is the relativistically corrected accelerating voltage in volts. It should be mention that the

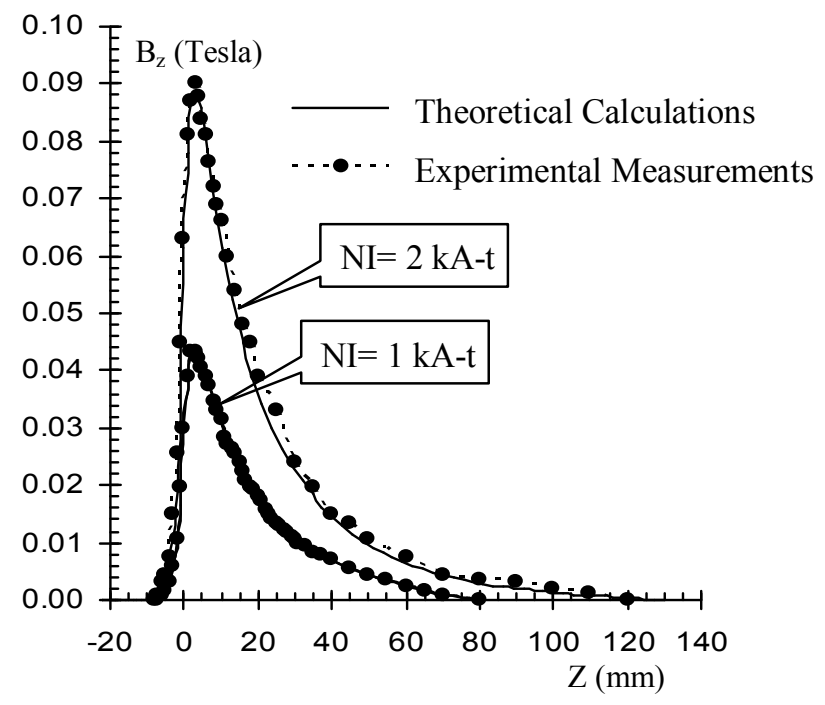

Fig. 5. Comparison between the values of $\mathrm{B}_{\mathrm{z}}$ as a function of $\mathrm{z}$ for $\mathrm{NI}=1 \mathrm{kA}-\mathrm{t}$ and $\mathrm{NI}=2 \mathrm{kA}-\mathrm{t}$.

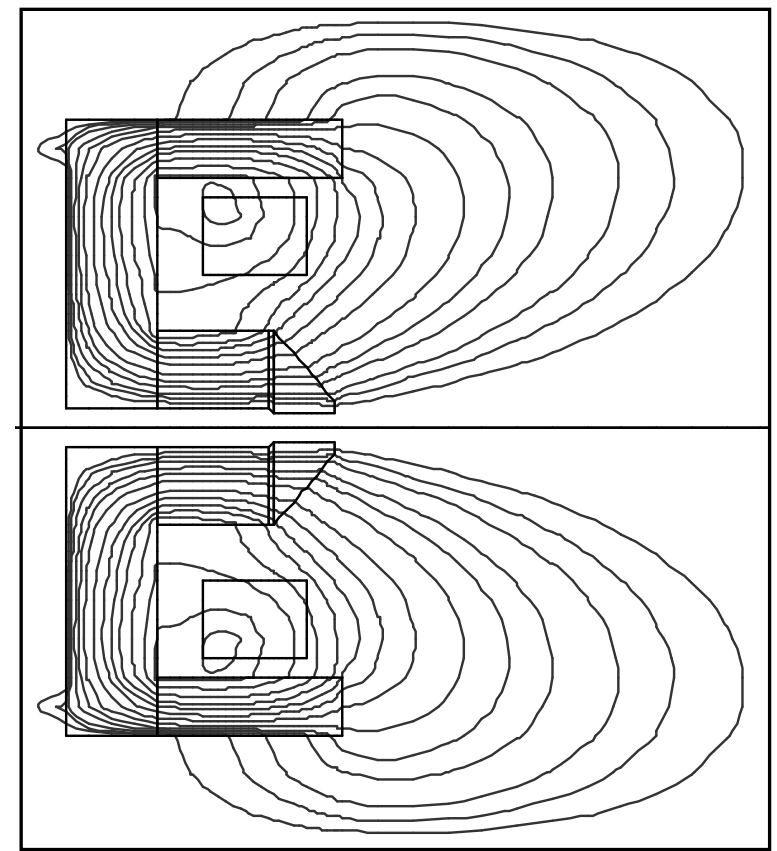

Fig. 6. Flux lines trajectories of the experimental single polepiece lens at constant excitation $(\mathrm{NI}=2 \mathrm{kA}-\mathrm{t})$. 
calculation has been taken in the direction of operation when the incident electron beam facing the back plate of the lens.

Figure 7 shows the variation of the objective focal properties (the spherical aberration coefficient $\mathrm{C}_{\mathrm{s}}$, the chromatic aberration coefficient $\mathrm{C}_{\mathrm{c}}$, and the objective focal length $f_{o}$ ) of the lens with the accelerating voltage $\mathrm{V}_{\mathrm{a}}$. It is seen from this figure that this lens acquired the lowest values of focal properties $\left(\mathrm{C}_{\mathrm{s}}, \mathrm{C}_{\mathrm{c}}, \mathrm{f}_{\mathrm{o}}\right)$ at accelerating voltage $\mathrm{V}_{\mathrm{a}} \leq 10 \mathrm{~V}$, and for $\mathrm{V}_{\mathrm{a}}>10 \mathrm{~V}$, the properties are increasing regularly. At $\mathrm{V}_{\mathrm{a}}=800 \mathrm{~V}$, the values of $\mathrm{C}_{\mathrm{s}}=\mathrm{C}_{\mathrm{c}}=1.2$ $\mathrm{mm}$. It can be noticed that the operating voltage of this lens is preferred when $\mathrm{V}_{\mathrm{a}} \leq 1000 \mathrm{~V}$.

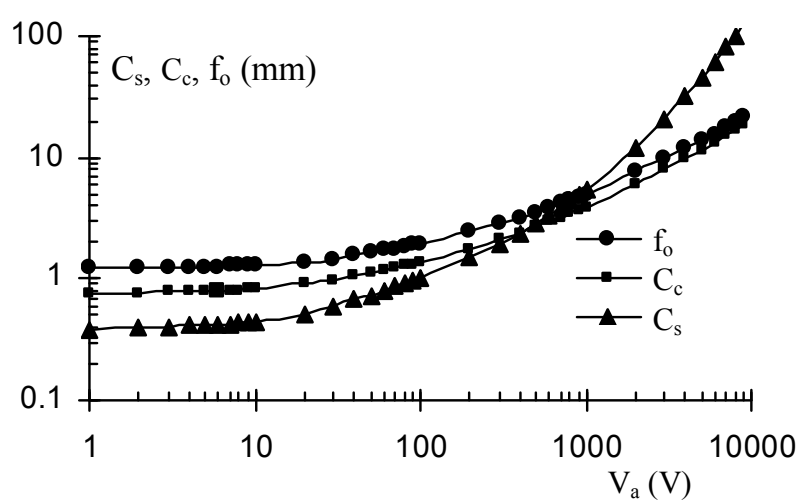

Fig. 7. The focal properties $\left(\mathrm{C}_{\mathrm{s}}, \mathrm{C}_{\mathrm{c}} \& \mathrm{f}_{\mathrm{o}}\right)$ of single polepiece lens as a function of accelerating voltage $\mathrm{V}_{\mathrm{a}}$.

In order to investigate the performance of the lens in more detail, it is necessary to consider the current density in coil windings for a lens exhibiting lower aberration coefficients. The limiting factor to the pole face flux density is, therefore, the current density that can be supported by the coil. The permissible current density in the windings up to $10^{6}$ $\mathrm{A}-\mathrm{t} / \mathrm{mm}^{2}$ can readily be achieved with superconducting windings [13].

The investigation has been carried out on the influence of the lens polepiece geometry on the resolving power. The calculated values of the resolving power $\left[\delta=0.7\left(\mathrm{C}_{\mathrm{s}} \lambda^{3}\right)^{1 / 4}\right]$ in $\mathrm{nm}$, where $\lambda$ is the electron wavelength of such lens operating at $V_{r}=2 M V$, as a function of the current densities in the windings $\sigma$ are presented in Figure 8. From this figure the lens exhibit different principal regimes, for low current densities less than $800 \mathrm{~A}-\mathrm{t} / \mathrm{mm}^{2}$. The resolving power $\delta$ decrease rapidly with the current density, while for higher current densities, between $\left(3 \times 10^{3}-10^{6}\right) \mathrm{A}$ $\mathrm{t} / \mathrm{mm}^{2}, \delta$ continue to fall at nearly the same rate. It can be noticed that the high resolving power occurs in the lens when $\delta=0.15 \mathrm{~nm}$ at $\sigma=3.3 \times 10^{5} \mathrm{~A}-\mathrm{t} / \mathrm{mm}^{2}$. This will represents the limiting resolving power that can be achieved in the fabricated lens.

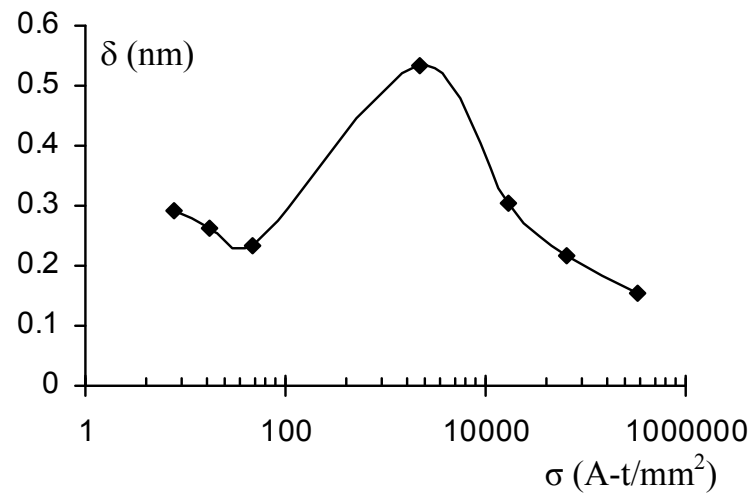

Fig. 8 . The variation of the resolving power $\delta$ of the single polepiece lens as a function of the current density $\sigma$

\section{Conclusions}

It appears that this lens has the lowest values of the objective focal properties at low accelerating voltage, less than $800 \mathrm{~V}$, these properties have nearly the same values at this voltage. So that this simple lens is suitable to be used as an objective lens in low voltage scanning electron microscope. 


\section{References}

[1] Mulvey, T. (1980), "Electron guns and instrumentation", Electron Microscopy, Vol.1, pp.46-53.

[2] Juma, S.M. and Mulvey, T. (1980), "The axial field distribution of single polepiece lenses", Inst. Phys. Conf. Ser. No.52, pp. 59-60.

[3] Mulvey, T. (1982), "Unconventional lens design", Magnetic Electron Lenses, P.W. Hawks, Ed., Springer-Verlag, Berlin, pp.359-420.

[4] Marai, F.Z. and Mulvey, T. (1976), 'Electron optical characteristics of single pole and related magnetic electron lenses", Development in Electron Microscopy and Analysis, Ed. J.A. Venables (London; Academic), pp. 43-44.

[5] Liebmann, G. (1955),'The field distribution in asymmetrical magnetic electron lenses", Proc. Phys. Soc., B 68, pp.679-681.

[6] Al-Obaidi, H. N. (1991), "Design of electromagnetic lenses", M.Sc. thesis, The University of Al-Mustansiriyah, Baghdad, Iraq.

[7] Al-Jumayli, F.A. (2010),"Design chroma corrected objective compound lens for low beam energies for scanning electron microscope", Ph.D. thesis, The University of Mosul, Mosul, Iraq, (To be published in July 2010).

[8] Al-Khashab M. A. and Al-Obaidy, K. Q. (2000), The theoretical limits of polepiece angle of the magnetic objective lens, J. Ed. Sci. 40, pp. 81-99.

[9] Lencova', B. (1986), "Program AMAG for computation of vector potential in rotationally symmetric magnetic electron lenses by FEM", Inst. Sci. Instrum. Czech. Acad. Sci. Brno. Czechoslovakia, pp.1-58.

[10] Al-Khashab, M.A. and Ahmad A.A.H., (2005), "Designing a doublet lens of optimized polepiece angle", Dirasat, Pure Sciences, Vol.32, No.2, pp. 182-187.

[11] Munro, E.,(1975), "A set of computer programs for calculating the properties of electron lenses", Cambridge University, Eng. Dept., Report Cued/B-ELECT/TR 45.

[12] Murad, M. (1997), "Design of iron-free magnetic electron lens", M.Sc. Thesis, The University of Mosul, Mosul, Iraq.

[13] Kamminga, W. (1976), "Properties of magnetic objective lenses with high saturated polepiece", Optik, Vol. 45, pp.39-54.

The work was carried out at the college of Engg. University of Mosul 